\title{
Editorial
}

\section{Final editorial 3 years of change}

Journal of Building Appraisal (2011) 6, 199-200. doi:10.1057/jba.2011.4

Journal of Building Appraisal will cease publication after this edition. The current editor has overseen published material for three of the six volumes published by Palgrave Macmillan. This final editorial will overview some of the things, which have changed in the UK building appraisal industry during the period of the last three volumes. These changes mostly result from revisions to existing legislation and revised codes of practice documents. These have altered client requirements and liabilities, and therefore impact on those who appraise buildings on their behalf.

Perhaps the biggest change to the entire construction industry was the advent of the new Construction Design and Management regulations (CDM 2007). These regulations extend the responsibility, first established by CDM 1994, for providing comprehensive health and safety information to clients and designers. The client now has overall responsibility for the successful management of health and safety practice during the entire contract, and ensure all appointments made are competent persons. Building appraisals undertaken where there is the prospect of future construction works, will now require to provide the client with additional information in respect of potential hazards on site, and whether the site is safe to undertake the proposed work upon. This information must be supplied by the client to designers and contractors. This potentially changes the nature of some surveys and the consequential reports from pre-CDM 2007 days, when contractors and site supervisors mostly managed health and safety issues. CDM 2005 puts a duty on the client to ensure all participants in the construction process from inception to completion are competent in terms of working safely and adhering to the regulatory requirements. This strengthens the professional's case for undertaking the work, but also removes the likelihood of the general surveyor adopting the role of CDM Coordinator for even small projects, as this has now become a more specialist role.

Very much tied to CDM are the new codes of practice for managing asbestos. The Health and Safety Executive (HSE), Approved Code of Practice (ACOP), Work with Materials Containing Asbestos, has provided a much more prescriptive set of instructions for those who tasked with being the duty holder for management of hazardous materials. It does, however, allow the duty holder to appoint a competent person to oversee asbestos management on their behalf. In terms of building appraisal, the increase in asbestos awareness had greatly increased the volume of specialist asbestos surveys. These will continue to be required, however, competence guidelines from a further HSE, ACOP, Asbestos: The Survey Guide mean that the depth of experience that a prospective asbestos surveyor and their practice must provide to prove competence will keep all but specialist asbestos surveyors away from doing this type of survey work.

The new ACOP has also seen a change to the range of surveys offered. The previous Types one, two and three surveys are replaced by the Management Survey and the Refurbishment and Demolition Survey. In real terms the latter is very similar to the old type three, and the former an amalgamation of types one and two. The new surveys solve the debate over the validity of type one surveys and take the main focus away from the survey towards the management plan. It is no longer essential to arrange for sampling of 
asbestos containing materials (ACMs), identified by means of a visual only survey (old type one), providing that the material is managed as being a confirmed ACM. The duty upon any professional building appraisers to identify potential ACMs during routine surveys still exists, and also the duty to read the asbestos register pre-survey and to comply with all management instructions throughout the inspection works.

One strike against established surveying practice contained in Asbestos: The Survey Guide is the removal of caveats. It has long been a surveyors practice to state limitations to a prospective survey, that is, areas that it is not possible to economically inspect. The new ACOP states that for asbestos surveying there should be no caveats, and if an area is not surveyed it must be managed as though live ACMs are present, until such time as it is proven that this is not the case. The editor awaits the impact of that regulation with interest, particularly in buildings requiring expensive access equipment to reach lofty areas.

It has long fallen to the surveyor to advise owners of sites containing elements of cultural heritage in respect of how they may use and develop their property. Hence, the final change to be reviewed is the death of PPG15, Planning and the Historic Environment 1994, and PPG16, Archaeology and Planning 1990, which for years provided planners with guidance in applications for planning permission in cases where culturally significant buildings or potential archaeology exist. The two PPGs directly conflicted as the most likely place to find archaeology is under or around a historic building, and therefore development of the building risked compromising any known or presumed archaeology. However, in March 2010, these were superseded by a new Planning Policy Statement, PPS5, Planning for the Historic Environment, 2010. The change between PPG and PPS is a simplification of guidance and a unification of the heritage asset. Listed buildings, archaeological finds, protected tress, protected landscapes, protected townscapes, protected ship wrecks, and so on are all classified as heritage assets. The theory is that different assets can be prioritised thus allowing planners to make a balanced decision that best protects the most important elements of a site. As stated good idea in theory, however, the new PPS5 is twinned with a very prescriptive document produced by English Heritage, PPS5 Planning for the Historic Environment, Historic Environment Planning Practice Guide, which does not always focus upon there being a priority system. Surveyors will need to learn the new philosophies and how to manage the process to ensure that appropriate development can still take place.

Things have changed and will continue to change, however, the Journal of Building Appraisal will no longer offer a vehicle for professionals to evaluate those changes as they occur. It is to be hoped that professional building appraisers will still continue to share their professional experience of dealing with these changes through academic and practice focused papers published in those journals that remain and those that will follow.

Simon Mclean Sheffield Hallam University, Nottinghamshire, UK 